Missing Pieces: Engaging Sociology of Disability in Medical Sociology (Forthcoming in Journal of Health and Social Behavior)

By Laura Mauldin and Robyn Lewis Brown

\title{
Missing Pieces: Engaging Sociology of Disability in Medical Sociology
}

\begin{abstract}
:
Medical sociologists and sociologists of disability study similar topics but, because of competing or conflicting theoretical paradigms, tend to arrive at different conclusions, engage with different audiences, and pursue different directions for social change. Despite diverging trajectories over the past 20 years, however, there remains clear potential overlap between both subfields in the study of disability and untapped opportunities for cross-fertilization. Our purpose here is to place these literatures in conversation with each other. Toward this end, we identify major themes in the last 20 years of medical sociology scholarship, gaps with regard to disability in those themes, and possibilities (including methodologies) we see at the intersection of medical sociology and the sociology of disability that could address these gaps.
\end{abstract}


Missing Pieces: Engaging Sociology of Disability in Medical Sociology (Forthcoming in Journal of Health and Social Behavior)

By Laura Mauldin and Robyn Lewis Brown

\section{Missing Pieces: Engaging Sociology of Disability in Medical Sociology}

In 2014, the most recent year for which Census data is available, 85.3 million communitydwelling people - more than one-quarter (27\%) of the U.S. population - had a disability (Taylor 2018). Although prevalence rates vary based upon the definition of disability used, the consistent measures utilized by the Census indicate an increase in the proportion of the population with a disability. ${ }^{1}$ Because this special issue highlights changes in the past 20 years, it is notable that the estimated percentage of the population in 2000 with a disability was about $10 \%$ less than it is today, at 18\% (Steinmetz 2006). There are a variety of reasons for increases in disability rates, such as advances in medical technologies resulting in children and adults living longer and with more complex conditions (Vincent and Velkoff 2010), as well as it being a phenomenon entangled with worsening inequality (NCD 2017). Furthermore, chronic illness has eclipsed acute illnesses in prevalence (Vincent and Velkoff 2010) and the COVID-19 pandemic is generating millions of new disabled people known as "long-haulers" who will join the disability community (Vastag and Mazur 2020; Wong 2020). This rising prevalence of disability has led some to argue that disability has become a "new normal" (Ginsburg and Rapp 2017).

The increased prevalence of disability in the population has made it more central to the field of medical sociology than in the past. This trend has emerged over the past 20 years and gained momentum in the past decade. Even 10 years ago, for example, Hankin and Wright's (2010:S11) 50 -year look back on medical sociology published in this journal did not discuss disability at all except for saying, "Health status, disease, disability, and death vary across social groups." While the medical sociology community has developed more sophisticated conceptual understandings of disability and methodological innovations, it is also critical to reflexively ask ourselves what we are doing and how we could do better. In this paper, we identify major themes in the last 20 years of medical sociology scholarship, gaps with regard to disability in those themes, and possibilities (including methodologies) we see at the intersection of medical sociology and the sociology of disability that could address these gaps.

As noted in the above statistics, disability is everywhere. This is particularly true if you consider the forms disability takes, including self-defined or legally-defined disability status, the presence of limitations in activities of daily living (ADLs), and challenges in performing more complex instrumental activities of daily living (IADLs) (Altman and Barnartt 2001). Throughout this paper, we use disability inclusively; it refers to both chronic illness and typically-defined disability categories related to self-defined disability status, and the presence of ADLs and IADLs. We do so because various laws and government programs in the U.S., as well as national and global health and disability organizations, define disability in relation to both physical and mental bodily functions, which would clearly include chronic illness (Thomas 2007).

\section{BRINGING DISABILITY IN}

Rising disability rates have corresponded with greater scholarly interest in experiences of disability and illness. Interestingly, the experience of illness and disability did not feature prominently in manuscripts published in this journal 20 years ago. In all of 2000, just four articles, or about $14 \%$ of Volume 41, grappled variously with self-assessed health, disease, and 
Missing Pieces: Engaging Sociology of Disability in Medical Sociology (Forthcoming in Journal of Health and Social Behavior)

By Laura Mauldin and Robyn Lewis Brown

physical health or functional limitations. In contrast, last year, 14 articles, about $45 \%$ of Volume 60 , explored these and related topics. Overall, three influential themes about disability have emerged in medical sociology in the past 20 years. They have (a) emphasized sociodemographic variation, as highlighted in the literatures on fundamental cause theory and the etiological role of social stress in health disparities; (b) outlined challenges to medical authority, medicalization, and the medical field's practical limits; and (c) elaborated our understanding of illness experiences.

In brief, research in the past 20 years on social stress (Thoits 2010) and work applying fundamental cause theory share a critical understanding of the salience of individual risk and protective factors for health (Phelan et al. 2004). These perspectives suggest that an individualized focus obscures the dynamic and multifaceted mechanisms that connect social environments and social conditions to health (Phelan et al. 2004; Thoits 2010). Paralleling these developments, research on medicalization and medical authority documented how technoscientific and economic structuring and organizational changes to medical care have diminished clinicians' power and enhanced the role of patient-consumers and corporate influences on medicalization processes (Clarke et al. 2003; Conrad 2005). This work has especially emphasized the major role that pharmaceutical companies play in marketing illnesses and their respective medications and the commodification of health insurance, medication, and health care services (Clarke et al. 2003; Conrad 2005). Elsewhere, scholars have applied symbolic interactionist and social constructionist frames to document experiences with illness. Elaborating on earlier work concerning cultural meanings of illness, more recent work explores the dimensionality of stigma and labeling processes and identity work among people with chronic physical and mental health conditions (Brown 2017; Thoits 2016).

A common theme in these research threads is that they typically talk around disability rather than about disability. As such, the actual experiences of people with disabilities and issues concerning categorical differences and inequalities experienced by people with disabilities have received significantly less theoretical and empirical attention within medical sociology. Such an omission is striking given the focus of recent stress research and fundamental cause scholarship on how the experience of health and illness is shaped by categories like gender, race-ethnicity, and sexual orientation (Bränström, Hatzenbuehler, and Pachankis 2016; DeAngelis 2020; Umberson et al. 2016). While this work has yielded important insights, issues related to disability as a minority category have often been relegated to the interdisciplinary field of disability studies (DS) and the more marginalized (within sociology) sociology of disability subfield. A danger of this lack of representation in the broader medical sociological literature is that it tends to lead to cultural and political misrepresentation of disability and, as social justice scholars warn, sidesteps the institutionalized obstacles that prevent some people from achieving participatory parity (Fraser 2008). Our purpose here is to demonstrate how a sociology of disability perspective can enrich these three medical sociology subfields.

\title{
DIVERGENCES AND CONVERGENCES BETWEEN THE SUBFIELDS
}

\author{
Mapping What Sociology of Disability Does
}


Missing Pieces: Engaging Sociology of Disability in Medical Sociology (Forthcoming in Journal of Health and Social Behavior)

By Laura Mauldin and Robyn Lewis Brown

In contrast to medical sociology, the sociology of disability has a conceptualization of disability informed by distinct theoretical foundations and research aims. While disability is still understood as a "health status," it is emphasized primarily as a unique social category (commensurate with race, class, or gender) made up of a heterogenous and expansive population with varying impairments or diagnoses (Frederick and Shifrer 2018; Naples, Mauldin, and Dillaway 2019). This does not mean that specific diagnoses or impairments are irrelevant, but that these usually serve as an organizational feature of research. For example, the particular experiences of those sharing a disability type might be taken up in an empirical study, but such a study would not only be about better understanding that specific condition and subpopulation, but also about expanding scholarship committed to the larger goal of theorizing and understanding disability as a social category. Disability is thus not solely constituted as a medical classification; rather, it is positioned as an axis of inequality decoupled from any particular impairment.

A quick survey across the subfield demonstrates how framing disability as an axis of inequality and social category is central. Scholars emphasize how structural factors and social norms produce individual and community experiences (e.g., Altman and Barnartt 2001; Thomas 2007). They measure the exclusion of disabled people, such as their high unemployment rates (Maroto and Pettinicchio 2014), the inaccessibility of healthcare systems (Meade, Mahmoudi, and Lee 2015), and adhere to the tenet that "disability is both a cause and consequence of poverty" (DFID 2000:1). Structural arrangements are also analyzed for their disproportionate effects on disabled people. In the U.S., for example, a lack of a universal healthcare system and a byzantine and highly restrictive system of support for disabled people (i.e., programs such as Social Security Disability Insurance and Medicaid) entraps disabled people financially and geographically (Grossman 2019; Stapleton et al. 2006). Scholars in this subfield also document how disability produces culture and identity (e.g., Grue 2016; Mauldin and Fannon 2020).

Importantly, sociologists have been examining disability for decades. In their volume of Research in Social Science and Disability, Green and Barnartt (2017) curate a rich set of articles detailing the often-overlooked histories of disability in sociology and trace a path back from the more recent sociology of disability research to seminal scholarship analyses. Overall, in the sociology of disability subfield, even when particular impairments are studied, there is an appreciation for how disability as a broad social category is structurally produced, characterized by profound inequality, and intersecting with other axes of inequality (Frederick and Shifrer 2018; Naples et al. 2019). In much the same way that medical sociologists acknowledge that health disparities involve a substantial array of often overlapping physical, psychological, intellectual, and behavioral health conditions, scholars working in the subfield also tend to adapt a similarly inclusive frame of what constitutes a disability. ${ }^{2}$

\section{The Role of Disability Studies}

In order to understand how the sociology of disability came to have these features, it is necessary to locate its roots in the history of the disability rights movement and the emergence of the interdisciplinary field of disability studies (DS). As the disability rights movement in the midtwentieth century coalesced around the mantra of "nothing about us without us" to protest 
Missing Pieces: Engaging Sociology of Disability in Medical Sociology (Forthcoming in Journal of Health and Social Behavior)

By Laura Mauldin and Robyn Lewis Brown

societal exclusion (Shapiro 1994), these activist roots later developed into the interdisciplinary field of DS in the 1980s (Shakespeare 2013). Importantly, this movement was not organized around any one particular impairment, but rather around disability as a category writ large. While different impairments may have specific challenges or particular needs, the movement coalesced around the broad social exclusion of disabled people regardless of impairment even as movements organized around particular impairment types co-occurred (e.g., Barnartt and Christiansen's (2003) work charting the Deaf cultural movement).

Simi Linton's (1998:1) foundational text, Claiming Disability, articulated DS as "a location and a means to think critically about disability, a juncture that can serve both academic discourse and social change." Importantly, she notes that many disciplines study disability, but DS was about reclaiming disability as an aspect of identity and recognizing disability as socially constructed. This articulation is still important; scholars may study disability, but they may not necessarily be engaging in DS. Fifteen years later, Rosemarie Garland-Thomson (2013) published a seminal piece articulating DS as a field already emerged. She categorizes DS as part of the first wave of "identity studies fields," noting that the "expansion beyond health science perspectives on disability to consider it a civil and human rights issue, a minority identity, a sociological formation, a historical community, a diversity group, and a category of critical analysis in culture and the arts constitutes the signature move of critical disability studies" (2013:917). Today, while the disability rights and disability justice movements that were crucial to the emergence of DS persist, there are both activist and scholarly communities. Scholars in DS work across a variety of intellectual traditions (the majority of which are in the humanities or "area studies"). For example, Disability Studies Quarterly, the flagship journal of the Society for Disability Studies, publishes work across fields like history, literary criticism, and cultural studies, as well as the social sciences. The journal Disability \& Society is more social science based.

An important piece of the disability rights movement and DS history that may not be known by medical sociologists, however, is that the beginnings of DS were grounded in sociology. The foundational idea that built upon the disability rights movement was the "social model of disability," which was articulated by British sociologist Michael Oliver in 1983 (Shakespeare 2013). The social model argues that disability is socially produced through structural and cultural arrangements that exclude individuals with various types of impairments. The distinction between impairment and disability is central; disability is a social process, not an inevitable or "natural" result of an individual's impairment. These social processes highlight the sociological aspects of disability: "[It] goes beyond the personal limitations that impaired individuals may face, to social restrictions imposed by an unthinking society. Disability is understood as a social and political issue rather than a medical one" (Oliver 1998:1446). The social model, despite criticisms, still undergirds disability studies, although recent scholarship has yielded nuanced theorization (e.g., Kafer 2013; McRuer 2018; Mitchell and Snyder 2015; Shakespeare 2006).

To further demonstrate the sociological roots of DS, revered medical sociologist Irving Zola was one of the founders of the Society for Disability Studies (for a review, see Scotch 2002) in the U.S. and pioneered much of the early work at the nexus of medical sociology and disability studies (e.g., Zola (1982), including in this journal (Zola 1991)). Despite the role of sociologyincluding medical sociology — in the founding of DS, important intellectual and institutional 
barriers have hindered the development of the sociology of disability subfield. Green (2017) outlined how the American Sociological Association (ASA) rejected calls for a section on disability until 2010, rendering the subfield only a very recent development. Green (2017) suggests that this bureaucratic resistance, rather than being negligible, reflects larger disciplinary practices of marginalization of disability and has had a role in perpetuating it. This is because the larger discipline tends to think of disability only as a niche "area study" rather than an axis of inequality core to the discipline's commitment to understanding stratification and power. There is also no sociological journal that can be claimed as a "home" for disability scholarship, making it difficult to place disability scholarship in the discipline. No sociology programs specialize in disability (a review of the ASA website shows that even the Section on Disability in Society refers sociologists and students to interdisciplinary disability studies programs), and this in turn leads to a diminished pipeline of graduate students in sociology that study disability.

While social and political aspects of health/illness are within the purview of medical sociology and sociology of disability, disability scholarship has not been easily absorbed into medical sociology. Indeed, there is often a gulf between these subfields related to how social and political aspects of disability are conceptualized, analyzed, and interpreted. To explain why that is, Thomas (2007) describes two competing frames: Medical sociology, informed by symbolic interactionism, frames disability as social deviance, while sociology of disability, informed by disability studies, frames disability as social oppression. Past scholarship on disability in medical sociology adheres to a more individual or medical model of disability. One could link this to the influence of Parsons' sick role (1951) to symbolic interactionism and its links with stigma (for further analysis, see Barnartt 2016). Even though medical sociology has moved beyond the sick role, an "overarching social deviance paradigm" (Thomas 2007:15) persists in framing disability as individual deviance. Thomas (2007:135) suggests that medical sociological scholarship on disability or chronic illness would be better classified as research on "impairment effects."

Meanwhile, as DS scholarship develops, deeper theorizing is beginning to cultivate a disability analytic as a mode of analysis rather than only a subject area specialization (Minich 2016; Schalk 2017). Minich (2016:no pg) describes how this analytic "involves scrutinizing not bodily or mental impairments but the social norms that define particular attributes as impairments, as well as the social conditions that concentrate stigmatized attributes in particular populations." In other words, we can view a disability analytic as an approach or perspective, not just research that focuses on disabled people (Schalk 2017). As Friedner and Weingarten (2019:485) further note: "Whereas "women" might have once been the object of focus for feminist theory, or "black people" might have been an object of focus for critical race theory, or "queer people" for queer theory, as each of these fields developed, theorists began expanding feminist theory, critical race theory, and queer theory to consider how these theories could help us understand systems of power, underlying assumptions, and also the absence of historically marginalized groups in texts or situations."

The development of this analytic, as we detail below, is seen in a shift to focusing on ableism, in addition to seeing disability as a social category. As these developments move forward in other disciplines, sociology — and particularly medical sociology — has yet to meaningfully take up such theoretical questions and integrate them into analyses. In a recent literature review of the 
Missing Pieces: Engaging Sociology of Disability in Medical Sociology (Forthcoming in Journal of Health and Social Behavior)

By Laura Mauldin and Robyn Lewis Brown

highest-ranking generalist sociology and medical sociology journals, Stoll and Egner (2021) find that sociologists largely fail to employ a critical approach when studying disability. Certainly, there are more complicated questions regarding how sub-specialties in sociology should relate to other "area studies" fields; here, we articulate productive and identifiable steps that could be taken to bring sociology up to date with the broad array of other disciplines that have taken DS seriously. In the following section, we demonstrate specific ways a disability analytic could address gaps in the three major themes in medical sociology research of the past 20 years previously noted.

\section{A DISABILITY ANALYTIC: ADDRESSING GAPS IN MEDICAL SOCIOLOGY}

\section{Extending the Literature on Fundamental Cause and Social Stress}

Although the literatures applying fundamental cause and social stress theories are concerned with status differences and social conditions, one glaring gap is the lack of engagement with disability as an axis of inequality. An exception is research on disability and stigma in these literatures, in its acknowledgment that many health conditions represent potent forms of social disadvantage that expose individual to status loss, discrimination, and resulting feelings of social devaluation (for a review, see Phelan et al. 2008). But, even this literature has not engaged with the concept of ableism. As disability scholarship has progressed, there has been a shift towards conceptualizing ableism, which "like other "isms" such as racism and sexism, describes discrimination towards a social group, in this case disabled people, but it also describes how certain ideals and attributes are valued or not valued" (Friedman and Owen 2017). Campbell (2009) and Wolbring (2008) both emphasize that ableism is more than a preference for nondisability, but instead is a set of values, institutionalized and codified into systems and structures, that privilege certain bodies/minds and features over others. Wolbring (2008:253) goes so far as to say that ableism is the "umbrella-ism" upon which other -isms like racism are based. This is echoed by recent disability justice work by Lewis (2019) who identifies ableism as "rooted in anti-Blackness, eugenics, colonialism and capitalism" and defines ableism as "a system that places value on people's bodies and minds based on socially constructed ideas of normalcy, intelligence, and excellence. . .One does not need to be disabled to experience ableism."

Taking ableism seriously in medical sociology would assist in a better understanding of illness and disability experiences, particularly those of disabled people of color, in healthcare settings (and beyond). For example, the COVID-19 pandemic laid bare how disabled people are targeted as a broad category, with multiple states releasing triage plans where disabled people would be excluded from receiving treatment (DREDF 2020). A recent incident, captured on video, revealed a Black disabled man denied treatment for COVID-19 because, as the doctor put it, "He did not have a quality of life" because he was paralyzed prior to acquiring COVID-19 (Roberts 2020). Disability scholars have long critiqued the notion of "quality of life" and argued that ableism is endemic to medical education, clinical interactions, and medical decision-making (Longmore 1995; Peace 2012), but such processes remain largely unexamined in medical sociological research. 
Missing Pieces: Engaging Sociology of Disability in Medical Sociology (Forthcoming in Journal of Health and Social Behavior)

By Laura Mauldin and Robyn Lewis Brown

Meanwhile, the impacts of bias such as racism and sexism are already well accepted as stressors that adversely affect health (Anderson 2013; Perry, Harp, and Oser 2013), and the experiences of stigma and discrimination are described as a fundamental cause of health inequities (Hatzenbuehler et al. 2013). Medical sociologists have shown that healthcare providers possess the same level of bias as the general population and that this bias affects health outcomes. In a systematic review of the literature, implicit bias was found to be "significantly related to patientprovider interactions, treatment decisions, treatment adherence, and patient health outcomes" (Hall et al. 2015:e60). While medical sociologists have rarely addressed biases regarding disability and ableism that providers bring to their work, disability scholarship shows that providers and students in medical school overwhelmingly possess ableist attitudes that affect their interactions with patients and determinations about "quality of life" (e.g., Saxton 2000). We are not suggesting a competition of -isms, but that discriminatory systems interlock and that ableism plays a key role in this interlocking that has thus far been largely ignored. Areas such as health services research and medical education should consider disability when looking at disparities in care and outcomes, as well as ableism as an important form of bias to investigate.

Like other minority groups, people with disabilities experience health disparities that are not functions of their condition, but that derive from ableism that often goes unrecognized (e.g., Iezzoni 2011; Krahn, Walker, and Correa-De-Araujo 2015). Interestingly, recent literature on countering the negative effects of racism suggests that positive cultural identification, strong community ties, and a positive self-concept are possible interventions that may help mitigate disparities (Okeke-Adeyanju et al. 2014). Likewise, studies indicate that positive disability identification contributes to healthy self-concept, self-esteem, and increases in well-being (Conrad and Barker 2010; Lumsdaine and Thurston 2017). The large body of scholarship in medical sociology that exists on these issues offers a unique opportunity to engage discussions of ableism and contribute to understandings of how disability and ableism appear in the structure and culture of healthcare and, among other things, affect outcomes.

\section{Extending the Literature on Medicalization and Medical Authority}

Another major strand of research concerns medicalization and medical authority, particularly the ways in which medicalization processes have changed and medical authority shifted (see Clarke et al. 2003; Conrad 2005). Medicalization has been a central concern to disability scholarship because the social model, a critique of an individual or medical model of disability, can be fundamentally understood as a critique of medicalization. That is, medicalization studies are partly rooted in a disability analytic. Echoes of this (while not explicitly stated) are particularly apparent in Zola's (1972) original conceptualization of medicalization arguing that it depoliticizes and individualizes, which Conrad (2005) later noted results in the narrowing of what is acceptable as "normal" in society. The interconnected roots of medicalization studies and disability studies can be seen in Rothman's Tentative Pregnancy (1993), in which she identifies ableism in the clinical culture surrounding amniocentesis. More recently, research has emerged on whether and the extent to which certain conditions should be medicalized (e.g., Blum 2015; Davis 2015; Mauldin 2016) and how medicalization relates to the politics and experiences of disability. Incorporating critiques of ableism would further extend medicalization studies in productive ways, such as by asking how the larger "engines of medicalization" (Conrad 2005:7) 
Missing Pieces: Engaging Sociology of Disability in Medical Sociology (Forthcoming in Journal of Health and Social Behavior)

By Laura Mauldin and Robyn Lewis Brown

are ideologically fueled by ableism. This could lead to examination of how belief systems about disability and which bodies or minds are desirable motivate medicalization and public acceptance or rejection of it.

Conrad (2005) also states that industries such as pharmaceuticals, biotechnologies, genetics, and enhancement are spurring medicalization. There is a rich literature at the intersection of disability studies and science and technology studies (STS) that demonstrate how a disability analytic can assist in identifying the intersection of disability and normalization tactics in particular technologies and industries and how biotechnologies are co-constitutive of disabilities that have direct effects on disability identities (e.g., Forlano 2017; Moser 2006; Winance 2016). For example, Mauldin (2016) writes about the emergence of the technology of cochlear implants and how their existence changed not only what constituted "good care" when it came to rearing deaf children, but redefined deafness to a brain processing problem. In STS, technologies are seen as part of the overall constitutive process of what disability is, how individuals "should" respond to it, and demonstrate that ableism is often the answer to why we pursue such technological endeavors in the first place. This offers possibilities for medical sociology to further understand such processes of medicalization and biomedicalization.

Scholarship in medicalization and medical authority has also revealed the shift from passive patients to active "consumers" and social agents. Conrad (2005) notes that structural shifts in favor of biotech, big pharma, and managed care often take agency from social movements and interest groups. Taken at face value, and without a more nuanced understanding of the context of Conrad's work, these shifts could be viewed as new phenomena. However, it must be acknowledged that Conrad's work is informed by decades of scholarship on disability social movements demonstrating the creative persistence of numerous movements in responding to such pressures (e.g., Barnartt and Scotch 2001; Grue 2016). Indeed, earlier sociological work wasn't just about social movements; it emerged as a direct result of them (Shakespeare 2013). In the U.S. today, disability justice movements are increasingly shaping the field of disability studies, too (e.g., Berne, Morales, and Langstaff 2018). We suggest that medical sociologists examining disability and illness communities mindfully incorporate scholarship about or direct movement work by those with disabilities.

Finally, another site of convergence related to social movements and disability absent in medical sociology has to do with the lack of care infrastructure in the U.S. and, for example, the Affordable Care Act (ACA). We wish to point out the potential of political affinity between what might be thought of as illness, aging, and disability communities, especially as they converge around the politics of healthcare in the U.S. in the context of neoliberalism. The recent fight to preserve the ACA is a political phenomenon ripe for analysis through a disability analytic, as are fights for universal home care. Cranford's (2020) recent work shows how disabled people and ill and/or aging folks are actively aligning in order to fight for more adequate home care funding in the U.S. This is particularly important now as more than $42 \%$ of all COVID cases are linked to nursing home residents or staff (Centers for Medicaid and Medicare Services 2021). We need more work showing how ableist ideologies underpinning neoliberal thinking and policies (i.e., only "productive" bodies are valuable) result in growing movements born out of political affinities between chronically ill, aging, and disabled folks. 
Missing Pieces: Engaging Sociology of Disability in Medical Sociology (Forthcoming in Journal of Health and Social Behavior)

By Laura Mauldin and Robyn Lewis Brown

This is further buttressed by recent work by Charmaz (2020) who writes that we must situate stigmatizing processes within larger structural arrangements, particularly within neoliberalism. On this Charmaz (2020) is correct, but there is already much work in disability studies that has put forward these theoretical analyses (e.g., Chaudhry 2015; Erevelles 2011; Goodley and Lawthom 2019; McRuer 2018; Mitchell and Snyder 2015). Broadly, this literature argues that neoliberalism is dependent upon ableism: "Ableism accounts for the stifling practices associated with a contemporary society that increasingly seeks to promote the species typical individual citizen: a citizen that is ready and able to work, productively contribute, an atomistic phenomenon bounded and cut off from others, capable, malleable and compliant" (Goodley and Lawthom 2019:235). Scholars writing on these issues suggest that "the absolute centrality of disability to a now global politics of austerity has rarely been theorized explicitly or comprehensively" (McRuer 2018:4). This literature could aid sociologists in expanding theoretically and empirically on this front.

\section{Extending the Literature on Experience and Social Construction of Illness}

The study of illness experiences has also been key to the sociology of health/illness in the last 20 years. The social deviance frame of disability in medical sociology persisted under the influence of symbolic interactionism in the sociology of health/illness, where a central line of inquiry became understanding how illnesses are socially constructed and how these meanings shape the experiences of people living with one - considering, for example, the extent of disability, time spent disabled, and the timing in life of disability onset (Susman 1994). This can be seen in the many earlier works (e.g., Charmaz 1993) that examined chronic illness primarily as disruption and stigma management at the individual level. Works in this strand, however, often leave out the role of social and structural aspects of ableism, and especially what disability studies scholars refer to as "internalized ableism" (Campbell 2008:156), wherein negative internalized notions about disability result in attempts to pass as able-bodied, lowered expectations of the self, and disdain for "dependency." Indeed, one of the tenets of ableism is a fetishistic prizing of "independence," seen in Charmaz's study where disability was so devalued that for her ill participants "dependency remains a greater specter than death" (Charmaz 1993:80). This phenomenon has yet to be deeply engaged with in medical sociology.

Earlier studies on stigma management also dovetail with scholarship investigating how people who experience chronic illness or disability seek or oppose a disability label and under what circumstances. Charmaz's (1993) study suggested that the label of disability was fraught with stigma and negative association. Other work delves into the complexity of self-identifying as disabled in greater detail. Perhaps the most direct response to work equating disability with stigma is that which indicates that the label of disability can provide a sense of relief as a way to organize a set of symptoms and adapt to changing circumstances (Gilmore and Somerville 1994). Others document the importance of social experiences even when accounting for changes in health: For example, Kelley-Moore and colleagues (2006) show that self-identification as disabled is associated with changes in social networks, home care, reciprocity in social relationships, and the ability to access social activities, and not simply with health changes. Elsewhere, disability scholars like Allison Carey (2009) have shown how disability social 
Missing Pieces: Engaging Sociology of Disability in Medical Sociology (Forthcoming in Journal of Health and Social Behavior)

By Laura Mauldin and Robyn Lewis Brown

movements utilized labels to forge alliances and gain access to services with regard to intellectual disability.

The stigma associated with the label of disability has received significant attention in research on the experience of mothering and disability, especially as it pertains to education. This work examines how disability is an axis of inequality that intersects with others, such as race. Blum (2015), for example, writes that Black mothers may be more resistant to labeling their child as disabled, while white mothers may have less resistance. Fish (2019) also writes about how these labels play out in school settings, particularly noting the intersection of race and disability. Because there are hierarchies of disability (i.e., some disabilities are more stigmatized than others), there are certainly more "high status" disabilities that may be attributed to white students.

We see hints of a nascent disability analytic in more recent scholarship focused on experiences with chronic illness that incorporate discussions of how chronically ill people may manage the issue of being identified as disabled. Barker (2005) briefly notes the tensions between legal definitions of disability and how stigma around drawing disability benefits negatively shapes opinions about those with fibromyalgia. This begins to hint at ableism and to locate disability within a structural frame; this is similar to Leiter's (2007) work on how disability is constructed through Early Intervention regulations and diagnostic categories, which in turn shape how families interact with systems. Kempner (2014) also engages with the larger cultural delegitimization around the chronically ill experience, especially as external ideologies about disability shape experiences of migraine. She argues that people with migraine do indeed experience it as a chronic, invisible disability, but they deal with trivialization and blame, expectations to overcome, and moral questions of deservedness. In short, she is describing ableism and hinting at how ableism constrains individuals with regard to diagnosis, labeling, and membership within the larger disability category. She also references the disability rights movement and how some in her study deploy the frame of disability and must defend against assumptions of laziness that often accompany beliefs about disabled people. More explicit engagement with ableism in the analysis of empirical data such as this has much to offer medical sociology; conversely medical sociologists potentially have much to offer in scholarship on disability.

Overall, we see potential for a shifting theoretical trajectory in medical sociology with regard to experiences of illness or disability. As Scambler and Scambler (2010) note, most studies of illness experience still focus on a personal tragedy model of illness - a medical model derivative - and generally adhere to a deviance paradigm. But the social deviance model of illness has been critiqued as inadequate by sociologists (Conrad and Barker 2010). Indeed, Charmaz (2020) articulates that the conceptualization of disability as deviance within the symbolic interactionist frame is a result of the influence of Goffman's work on stigma (Goffman 1963). Charmaz then engages the work of sociologist of disability Barnartt (2016), who critiques how stigma is seen as "stable" and casts disabled people as embodying a form of deviance and leaves it at that. Charmaz (2020) concedes that the symbolic interactionist tradition has generally ignored structural causes of disability oppression, but maintains that it is entirely possible - and desirable - for symbolic interactionists to contextualize interactions and experiences within 
Missing Pieces: Engaging Sociology of Disability in Medical Sociology (Forthcoming in Journal of Health and Social Behavior)

By Laura Mauldin and Robyn Lewis Brown

social structure. Such a reflection might signal an openness for the influence of what Thomas (2007) referred to as a social oppression frame, or what we have highlighted as a disability analytic, to be better integrated into the sociology of health/illness.

One way that disability scholarship could be better incorporated into the social construction of illness literature is to focus on the generative or transformative aspects, rather than it being about solely "tragic" notions of impairment effects or managing stigma. Disability scholarship documenting the experiences of disabled people reveals identity formation (Grue 2016; Linton 1998) and expertise. Disability expertise is an important concept for medical sociologists concerned with health, illness, and knowledge production. Disability expertise, put forth by Hartblay (2019:S34), a medical anthropologist trained in disability studies, is "the particular knowledge that disabled people develop and enact about unorthodox configurations of agency, cultural norms, and relationships between selves, bodies, and the designed world." Similarly, Mitchell and Snyder (2015:2) write that we must engage "the active transformation of life that the alternative corporealities of disability creatively entail." And as mentioned in the previous section, there is work in STS and disability that examines the ways in which technologies, particularly assistive technologies, prosthetics and so on, co-construct experiences of disability.

A frame of disability expertise positions disabled and ill people as knowledge producers and active agents in their lives, while stressing that their bodies/minds are in tension with structural arrangements not designed for them. How might deeper and more disability-informed analyses broaden the scope of understanding experiences of disability and/or chronic illness? How do disabled individuals come to navigate a world hostile to them, what does this reveal and how is it achieved? How is the ability to navigate inflected by intersections with race, class, and gender? We see these as questions that require greater collaboration between medical sociology and a sociology of disability to answer.

\section{DISABILITY INFORMED METHODOLOGIES}

Medical sociology and sociology of disability may also be enhanced by methodological crossfertilization. Several recent studies demonstrate the utility of a crossover approach, harnessing the predictive power of quantitative research to make generalizations within and across populations while retaining a disability-centric approach (Brown 2017; Brown and Moloney 2019; Latham-Mintus and Clarke 2019; Maroto and Pettinicchio 2014; Shandra, Hogan, and Short 2014; Shifrer 2013). Distinguishing this work is its use of population research methods to understand diversity within disabled populations using generalizable studies of people with disabilities. This approach is an important departure from most quantitative work on disability that compares people with and without disabilities within a population, which tends to endorse a deficit understanding of disability and blanketly assume and reify such assumptions that disabled people overall have poorer "quality of life" (Brown 2017). For example, in counterpoint to research indicating that people with disabilities have lower psychological well-being than people without disabilities, the within-population research shows that most people with disabilities report high levels of psychological well-being, and those that do not disproportionally experience severe economic and social disadvantages (Brown and Moloney 2019; Maroto and Pettinicchio 
Missing Pieces: Engaging Sociology of Disability in Medical Sociology (Forthcoming in Journal of Health and Social Behavior)

By Laura Mauldin and Robyn Lewis Brown

2014); educational inequalities (Shandra et al. 2014; Shifrer 2013); frequent exposure to discrimination (Brown 2017), etc.

One limitation of the aforementioned crossover research, however, is the disproportionate value given to qualitative and quantitative approaches. In much the same way that the National Institutes of Health $(\mathrm{NIH})$ now requires large-scale population studies to adopt a mixed methods approach, we endorse the value of sequential mixed methods research including qualitative approaches, as well as the importance of qualitative research more broadly. Indeed, the value of qualitative methods in previous disability studies research can hardly be overstated. Qualitative research has been essential to the scholarship on experiences of illness, doctor-patient interactions, and other areas in medical sociology. The dominance of qualitative work in the sociology of disability may be attributed to the subfield's emphasis on capturing and elevating experiences of disabled people, which qualitative methods are uniquely able to do.

\section{Incorporating Disability into Reflexivity}

Contemporary ethnographic methods are characterized by a commitment to reflexivity on the part of the researcher. While not all research projects in either subfield should employ qualitative research methods, we want to emphasize how knowledge from sociology of disability could factor into reflexivity practices in medical sociology research (regardless of whether it is a qualitative or quantitative study). Reflexivity is an examination of how biased assumptions of the researcher influence their design and interpretation of data (Berger 2013). As we have outlined above, it is not yet standard sociological thought that disability is an axis of inequality and that ableism is a culturally dominant value system and form of discrimination. Most sociologists are not trained to attend to their disability status as a factor in reflexivity, while simultaneously we are often taught to think about other social positions we occupy. Yet sociologists are not immune to bringing ableist assumptions into their work, and this can shape many aspects of the research process, including how disability is framed in research and how participant experiences of disability are asked about and interpreted.

In order to address the missing disability analytic in reflexivity practices, we recommend the following for all sociologists, but especially those researching disability and illness: (1) reflect on how common sense notions of disability as inherently undesirable or a deficit may influence all stages of research from how the questions are posed to paternalistic or pitying attitudes towards participants to myopic focus on the "tragedy" of disability; (2) be aware of assumptions that ill or disabled people do not have agency or are not knowledge producers (or that they are not also sociologists doing research and bringing unique and important perspectives to such work), and (3) inform oneself of the appropriate language to use when describing these communities.

We also recommend the following as ways that sociologists can begin to incorporate a disability analytic into their reflexivity practices: (1) noting and examining one's own disability status and committing to investigating and understanding how that shapes research; (2) investigating cultural knowledge produced by disability communities that one is studying; and (3) not solely seeking out and consulting "experts" on the populations one is studying without including disabled or ill people as part of the experts. Regarding our first recommendation, this is not to 
prescribe who can and cannot do research on ill or disabled communities, but rather a suggestion for researchers as to how to bring the social category of disability into our standard practices of reflexivity. Acknowledging one's disability status in the research design phase can assist in helping us reflect on the kinds of questions we ask participants, the kinds of frames we may choose to understand our data, and so on. One early example of this is Zola's Missing Pieces (1982), which includes deep reflection on his status as a disabled person and how this shaped the research. As stated earlier, disabled people possess expertise through their lived experiences and many become experts (and indeed contest the very notion of expert) and researchers themselves. We therefore recommend including disabled people from the populations being studied, whether through including them as research participants or consulting them as part of the research design team. If it is the latter, we endorse following the recommendation of federal funding agencies by appropriately compensating those individuals for that expertise. Integrating a disability analytic or consciousness into research practices means recognizing that disabled people are persistently marginalized in work about their own communities. When they are utilized informally as knowledge producers, they may rarely be financially compensated for it, furthering marginalizing practices that disenfranchise disabled people. Our recommended practices reflect a commitment to addressing ableism in research and a starting point for addressing it in sociological research.

\section{Disability Methodologies}

Sociology of disability scholarship has long grappled with the substantive focus of research and ways that a disability analytic can inform methodological choices, data collection procedures, and overall research goals. Oliver (1992), who developed the social model of disability, introduced "emancipatory research" as a critical form of inquiry and critical praxis (which he states is influenced by feminist methodologies). Oliver (1992:108) critiques the grounding of disability research on the individual as "seeing the problems that disabled people face as being caused by their individual impairments. These rock-bottom explanations not only see disability as an individual problem but in so doing they reject other possible explanations." More specifically, he (1992:102) describes the ethos of emancipatory research in following way:

Disability research should not be seen as a set of technical, objective procedures carried out by experts but part of the struggle by disabled people to challenge the oppression they currently experience in their daily lives. . .do researchers wish to join with disabled people and use their expertise and skills in their struggles against oppression or do they wish to continue to use these skills and expertise in ways in which disabled people find oppressive?

Barnes (2003) notes that emancipatory research overlaps with later methods like participatory action research. This body of methodological scholarship informed by a disability analytic could be useful to medical sociology.

Meanwhile, medical sociologists, such as Bell (2017), have also advocated for innovative qualitative methods, particularly visual methods, to be used to more seriously engage with the embodied experiences of disabled participants. There are also numerous other resources that 
discuss disability research, highlighting how to design inclusive research protocols and take various access needs of disabled people into account (e.g., Berger and Lorenz 2016). Other methodologists call for disabled participants to be actively involved in the co-construction of knowledge (e.g., Caldwell 2014). We share this information not to be prescriptive, but to make medical sociologists aware of such methodological debates over disability, especially as they reflect upon research design and goals.

\section{CONCLUSION: PUTTING THE PIECES TOGETHER}

There are substantive ways that the sociology of disability can extend three of the major areas constituting medical sociology scholarship in the last 20 years. In fundamental causes and social stress, we emphasize the need to see disability as an axis of inequality and to integrate an understanding of ableism into our analyses. In medicalization and medical authority, we highlight how disability studies is at the root of medicalization studies and suggest turning to disabled communities to examine the social movements well underway. We also suggest there are linkages across political groups, especially under neoliberalism, a philosophy that depends upon ableism for its logic. In the social construction of illness, we stress that ableism structures experiences of illness and that this logic should be better incorporated into this literature, as well as increased attention to the transformative and generative aspects of disability experience, culture-making, and disability expertise.

We are working at a time in which, for political and economic reasons, social programs for people with disabilities are being eliminated and it seems unlikely that we will see their return or enhancement in the near future. Within this context, it is paramount that we acknowledge that medical sociology and sociology of disability scholars are working toward the same basic goal, which is to enhance the lives of people with disabilities. The ways in which we have pursued this goal often differ, but they are not mutually exclusive. This is demonstrated by the more recent disability scholarship we noted employing population research methods to understand variation within disabled populations. This research suggests that the dialogue between these two subfields would be beneficial for both; we likewise encourage scholars in the sociology of disability subfield to take up healthcare and medicine more broadly in their work, as it is an important site of power and meaning-making for disability. Similarly, disability scholars would benefit from methodological and theoretical tools that medical sociologists have developed, particularly with regard to the premise that medicine is social. This can sometimes be obscured in disability scholarship if researchers, in seeking to avoid being focused on medicine as a way to prove their social model allegiance, ignore the important role medicine has in disabled people's lives.

However, cross-pollinations between these two subfields have too rarely occurred. We suggest that this is likely because of the different theoretical foundations in each subfield and a lack of discussion in sociology more broadly about disability and ableism as an axis of inequality. However, these tensions also reflect larger disciplinary arguments about what sociology is. As Mary Romero (2020:3) articulated in her 2019 ASA Presidential Address, "Our discipline has a long history of debating value-free objective sociology versus an engaged sociology aimed at change for a better world." Is sociology a discipline that produces "neutral" science? Or is it a discipline committed to social justice? It is clearly the case from our description above that the 
majority of the sociology of disability is committed to the latter. Its activist roots have very much shaped the formulation of the subfield, contributing to methodological ideas of emancipatory research and scholarship dedicated to documenting and amplifying the lives of disabled people. The goal of this work is often, though not exclusively, to enhance social programming and policy.

In contrast, medical sociologists are more varied, with some seeing their work as value-free and others considering theirs as more socially engaged or responsive. However, it is difficult to see the application of medical sociology scholarship as socially disengaged. Indeed, when medical sociologists consider the policy applications of their research, which are typically framed as recommendations for prevention or intervention programs, this is in itself a call for social action. But, our point is that without attending to the political context and recognizing ableism as a formative logic in our healthcare systems, programs, and policies and seeing disability as an axis of inequality, we are hamstrung in efforts to improve disabled people's lives. That is, without an understanding of disability informed by a critical analytic, we will find ourselves increasingly doing work that may either enable unequal systems or fail to articulate the urgent changes needed in our care systems and programs, all of which affect the majority of people's lives either directly or indirectly. 
Missing Pieces: Engaging Sociology of Disability in Medical Sociology (Forthcoming in Journal of Health and Social Behavior)

By Laura Mauldin and Robyn Lewis Brown

\section{Notes}

1. These rates are based upon the presence of impairments, activity limitations, and participation restrictions a person may experience due to disability, but are conservative estimates because they do not include institutionalized populations.

2. Admittedly, a challenge is that different disabilities are largely addressed in autonomous systems, infrastructures, and policies. This is partly why the trajectories of many social movements associated with psychological disability issues have diverged substantially from more mainstream disability rights movements and helps to explain the development of the mad studies subfield paralleling growth in disability studies. However, this split seems shortsighted for the simple reason that many people do not experience discrete disabilities. For example, one recent meta-analysis indicates that an estimated $36 \%$ of people with physical disabilities also experience a psychological disability (Daré et al. 2019). Analyses of the National Survey on Drug Use and Health further estimate the prevalence of substance misuse among people with physical disabilities at 40\% (Glazier and Kling 2013). There is considerably greater comorbidity even still between mental health and substance use related disorders, with the National Comorbidity Study and Replication indicating that the majority of substance use disorders are a consequence of primary psychological disabilities (Kessler et al. 1997; Merikangas et al. 2007). Thus, in much the same way that medical sociologists and scholars in the sociology of mental health address overlapping health conditions, DS scholars also grapple with the social problems and forms of oppression that are unique to those who experience not only various disability types but also multiple disabilities. 
Missing Pieces: Engaging Sociology of Disability in Medical Sociology (Forthcoming in Journal of Health and Social Behavior)

By Laura Mauldin and Robyn Lewis Brown

\section{References}

Altman, Barbara M., and Sharon N. Barnartt, eds. 2001. Exploring Theories and Expanding Methodologies: Where We Are and Where We Need to Go. Vol. 2. Bingley, UK: Emerald Group Publishing Limited.

Anderson, Kathryn Freeman. 2013. "Diagnosing Discrimination: Stress from Perceived Racism and the Mental and Physical Health Effects.” Sociological Inquiry 83(1):55-81.

Barker, Kristin. 2005. The Fibromyalgia Story: Medical Authority and Women's Worlds of Pain. Philadelphia, PA: Temple University Press.

Barnartt, Sharon. 2017. "How Erving Goffman Affected Perceptions of Disability within Sociology.” Pp. 29-37 in Research in Social Science and Disability, Vol 9. Sociology Looking at Disability: What Did We Know and When Did We Know It, edited by S. Green and S. Barnartt. Bingley, UK: Emerald Group Publishing Limited.

Barnartt, Sharon, and Richard Scotch. 2001. Disability Protests: Contentious Politics, 19701999. Washington, DC: Gallaudet University Press.

Barnes, Colin. 2003. "What a Difference a Decade Makes: Reflections on Doing "Emancipatory” Disability Research." Disability \& Society 18(1):3-17.

Bell, Susan. 2017. "Bringing Our Bodies and Ourselves Back in: Seeing Irving Kenneth Zola's Legacy." Pp. 143-58 in Research in Social Science and Disability, Vol. 9, Sociology Looking at Disability: What Did We Know and When Did We Know It, edited by S. Green and S. Barnartt. Bingley, UK: Emerald Group Publishing Limited.

Berger, Ronald J., and Laura S. Lorenz. 2016. Disability and Qualitative Inquiry: Methods for Rethinking an Ableist World. Burlington, VT: Routledge.

Berger, Roni. 2013. 'Now I See It, Now I Don't: Researcher's Position and Reflexivity in Qualitative Research" Qualitative Research 15(2):219-34.

Berne, Patricia, Aurora Levins Morales, and David Langstaff. 2018. “Ten Principles of Disability Justice.” WSQ: Women's Studies Quarterly 46(1):227-30.

Blum, Linda M. 2015. Raising Generation Rx: Mothering Kids with Invisible Disabilities in an Age of Inequality. New York, NY: NYU Press.

Bränström, Richard, Mark L. Hatzenbuehler, and John E. Pachankis. 2016. "Sexual Orientation Disparities in Physical Health: Age and Gender Effects in a Population-based Study." Social Psychiatry and Psychiatric Epidemiology 51(2):289-301.

Brown, Robyn Lewis. 2017. "Functional Limitation and Depressive Symptomatology: Considering Perceived Stigma and Discrimination within a Stress and Coping Framework." Stigma and Health 2(2):98-109. 
Missing Pieces: Engaging Sociology of Disability in Medical Sociology (Forthcoming in Journal of Health and Social Behavior)

By Laura Mauldin and Robyn Lewis Brown

Brown, Robyn Lewis, and Mairead Eastin Moloney. 2019. "Intersectionality, Work, and Wellbeing: The Effects of Gender and Disability." Gender \& Society 33(1):94-122.

Caldwell, Kate. 2014. "Dyadic Interviewing: A Technique Valuing Interdependence in Interviews with Individuals with Intellectual Disabilities." Qualitative Research 14(4):488-507.

Campbell, Fiona Kumari. 2008. "Exploring Internalized Ableism Using Critical Race Theory." Disability \& Society 23(2):151-62.

Campbell, Fiona Kumari. 2009. Contours of Ableism: The Production of Disability and Abledness. New York, NY: Palgrave Macmillan.

Carey, Allison C. 2009. On the Margins of Citizenship: Intellectual Disability and Civil Rights in Twentieth-Century America. Philadelphia, PA: Temple University Press.

Centers for Medicaid and Medicare Services. 2021. COVID-19 Nursing Home Data. Washington, D.C. Retrieved April 30, 2021. (https://data.cms.gov/stories/s/COVID-19Nursing-Home-Data/bkwz-xpvg/)

Charmaz, Kathy. 1993. Good Days, Bad Days: The Self and Chronic Illness in Time. New Brunswick, NJ: Rutgers University Press.

Charmaz, Kathy. 2020. "Experiencing Stigma and Exclusion: The Influence of Neoliberal Perspectives, Practices, and Policies on Living with Chronic Illness and Disability." Symbolic Interaction 43(1):21-45.

Chaudhry, Vandana. 2015. "Neoliberal Disorientations: Changing Landscapes of Disability and Governance in India." Disability \& Society 30(8):1158-73.

Clarke, Adele E., Janet K. Shim, Laura Mamo, Jennifer Ruth Fosket, and Jennifer R. Fishman. 2003. "Biomedicalization: Technoscientific Transformations of Health, Illness, and U.S. Biomedicine.” American Sociological Review 68(2):161-94.

Conrad, Peter. 2005. "The Shifting Engines of Medicalization.” Journal of Health and Social Behavior 46(1):3-14.

Conrad, Peter, and Kristin K. Barker. 2010. "The Social Construction of Illness: Key Insights and Policy Implications." Journal of Health and Social Behavior 51(Suppl):S67-S79.

Cranford, Cynthia J. 2020. Home Care Fault Lines: Understanding Tensions and Creating Alliances. Ithaca New York: ILR Press.

Daré, Labanté Outcha, Pierre-Emile Bruand, Daniel Gérard, Benoît Marin, Valerie Lameyre, Farid Boumédiène, and Pierre-Marie Preux. 2019. "Co-Morbidities of Mental Disorders 
Missing Pieces: Engaging Sociology of Disability in Medical Sociology (Forthcoming in Journal of Health and Social Behavior)

By Laura Mauldin and Robyn Lewis Brown

and Chronic Physical Diseases in Developing and Emerging Countries: A MetaAnalysis." BMC Public Health 19(1): 1-12.

Davis, Georgiann. 2015. Contesting Intersex: The Dubious Diagnosis. New York, NY: NYU Press.

DeAngelis, Reed T. 2020. "Striving While Black: Race and the Psychophysiology of Goal Pursuit." Journal of Health and Social Behavior 61(1):24-42.

Department for International Development (DFID). 2000. Disability, Poverty and Development. London, UK: Department for International Development.

Disability Rights Education \& Defense Fund (DREDF). 2020. Preventing Discrimination in the Treatment of COVID-19 Patients: The Illegality of Medical Rationing on the Basis of Disability—Disability Rights Education \& Defense Fund. Berkeley, CA: Disability Rights Education \& Defense Fund. Retrieved July 15, 2020. (https://dredf.org/theillegality-of-medical-rationing-on-the-basis-of-disability/).

Erevelles, Nirmala. 2011. Disability and Difference in Global Contexts: Enabling a Transformative Body Politic. New York, NY: Palgrave Macmillan.

Fish, Rachel Elizabeth. 2019. "Standing Out and Sorting In: Exploring the Role of Racial Composition in Racial Disparities in Special Education." American Educational Research Journal 56(6):2573-2608. doi: 10.3102/0002831219847966.

Forlano, Laura. 2017. "Maintaining, Repairing and Caring for the Multiple Subject." Continent 6(1):30-35.

Fraser, Nancy. 2008. “Abnormal Justice.” Critical Inquiry 34(3):393-422.

Frederick, Angela, and Dara Shifrer. 2018. "Race and Disability: From Analogy to Intersectionality." Sociology of Race and Ethnicity 15(2):200-214.

Friedman, Carli, and Aleksa L. Owen. 2017. "Defining Disability: Understandings of and Attitudes towards Ableism and Disability." Disability Studies Quarterly 37(1).

Friedner, Michele, and Karen Weingarten. 2019. "Introduction: Disorienting Disability." South Atlantic Quarterly 118(3):483-90.

Garland-Thomson, Rosemarie. 2013. "Disability Studies: A Field Emerged." American Quarterly 65(4):915-26. doi: 10.1353/aq.2013.0052. 
Missing Pieces: Engaging Sociology of Disability in Medical Sociology (Forthcoming in Journal of Health and Social Behavior)

By Laura Mauldin and Robyn Lewis Brown

Glazier, Raymond E., and Ryan N. Kling. 2013. "Recent Trends in Substance Abuse among Persons with Disabilities Compared to that of Persons without Disabilities." Disability and Health Journal 6(2): 107-115.

Green, Sara. 2017. "Foreword.” Pp. ix-xiii in Sociology Looking at Disability: What Did We Know and When Did We Know It? Edited by S. Green and S. Barnartt. Vol. 9. Bingley, U.K.: Emerald Group Publishing

Green, Sara and Sharon Barnartt, Eds. 2017. Sociology Looking at Disability: What Did We Know and When Did We Know It? Vol. 9. Bingley, U.K.: Emerald Group Publishing.

Gilmore, Norbert, and Margaret A. Somerville. 1994. "Stigmatization, Scapegoating and Discrimination in Diseases: Overcoming "Them" and "Us." Social Science \& Medicine 39(9):1339-58.

Ginsburg, Faye, and Rayna Rapp. 2017. "Cripping the New Normal: Making Disability Count." Alter 11(3):179-92.

Goffman, Erving. 1963. Stigma: Notes on the Management of Spoiled Identity. Englewood Cliffs, NJ: Prentice-Hall.

Goodley, Dan, and Rebecca Lawthom. 2019. "Critical Disability Studies, Brexit and Trump: A Time of Neoliberal-Ableism.” Rethinking History 23(2):233-51.

Grossman, Brian R. 2019. "Disability and Corporeal (Im)Mobility: How Interstate Variation in Medicaid Impacts the Cross-State Plans and Pursuits of Personal Care Attendant Service Users." Disability and Rehabilitation 41(25):3079-89.

Grue, Jan. 2016. "The Social Meaning of Disability: A Reflection on Categorisation, Stigma and Identity." Sociology of Health \& Illness 38(6):957-64.

Hall, William J., Mimi V. Chapman, Kent M. Lee, Yesenia M. Merino, Tainayah W. Thomas, B. Keith Payne, Eugenia Eng, Steven H. Day, and Tamera Coyne-Beasley. 2015. "Implicit Racial/Ethnic Bias Among Health Care Professionals and Its Influence on Health Care Outcomes: A Systematic Review." American Journal of Public Health 105(12):e60-e76.

Hankin, Janet R., and Eric R. Wright. 2010. "Reflections on Fifty Years of Medical Sociology." Journal of Health and Social Behavior 51(Suppl):S10-14.

Hartblay, Cassandra. 2019. "Disability Expertise: Claiming a Disability Anthropology." Current Anthropology 61(S21):S26-S36.

Hatzenbuehler, Mark L., Jo C. Phelan, and Bruce G. Link. 2013. "Stigma as a Fundamental Cause of Population Health Inequalities." American Journal of Public Health 103(5): 813-821. 
Missing Pieces: Engaging Sociology of Disability in Medical Sociology (Forthcoming in Journal of Health and Social Behavior)

By Laura Mauldin and Robyn Lewis Brown

Iezzoni, Lisa I. 2011. "Eliminating Health and Health Care Disparities among the Growing Population of People with Disabilities." Health Affairs 30(10):1947-54.

Kafer, Alison. 2013. Feminist, Queer, Crip. Bloomington, IN: Indiana University Press.

Kelley-Moore, Jessica A., John G. Schumacher, Eva Kahana, and Boaz Kahana. 2006. "When do Older Adults become "Disabled?" Social and Health Antecedents of Perceived Disability in a Panel Study of the Oldest Old." Journal of Health and Social Behavior 47(2):12641.

Kempner, Joanna. 2014. Not Tonight: Migraine and the Politics of Gender and Health. Chicago, IL: University of Chicago Press.

Kessler, Ronald C., Rosa M. Crum, Lynn A. Warner, Christopher B. Nelson, John Schulenberg, and James C. Anthony. 1997. "Lifetime Co-Occurrence of DSM-III-R Alcohol Abuse and Dependence with Other Psychiatric Disorders in the National Comorbidity Survey." Archives of General Psychiatry 54(4): 313-321.

Latham-Mintus, Kenzie, and Philippa J. Clarke. 2019. "Linking Mastery across the Life Course to Mobility Device Use in Later Life." The Journals of Gerontology, Series B: Psychological Sciences and Social Sciences 74(7):1222-32.

Leiter, Valerie. 2007. “"Nobody’s Just Normal, You Know”: The Social Creation of Developmental Disability." Social Science \& Medicine 65(8):1630-41.

Lewis, Talila T. L. 2019. "Longmore Lecture: Context, Clarity \& Grounding." Talila A. Lewis. Retrieved January 29, 2020. (http://www.talilalewis.com/1/post/2019/03/longmorelecture-context-clarity-grounding.html).

Linton, Simi. 1998. Claiming Disability: Knowledge and Identity. New York, NY: NYU Press.

Longmore, Paul K. 1995. "Medical Decision Making and People with Disabilities: A Clash of Cultures." The Journal of Law, Medicine \& Ethics: A Journal of the American Society of Law, Medicine \& Ethics 23(1):82-87.

Lumsdaine, Sally, and Mhairi Thurston. 2017. "Growing up in a Mainstream World: A Retrospective Enquiry into the Childhood Experiences of Young Adults with a Physical Disability." International Journal of Disability, Development and Education 64(2):18297.

Maroto, Michelle, and David Pettinicchio. 2014. "Disability, Structural Inequality, and Work: The Influence of Occupational Segregation on Earnings for People with Different Disabilities.” Research in Social Stratification and Mobility 38:76-92.

Mauldin, Laura. 2016. Made to Hear: Cochlear Implants and Raising Deaf Children. Minneapolis, MN: University of Minnesota Press. 
Missing Pieces: Engaging Sociology of Disability in Medical Sociology (Forthcoming in Journal of Health and Social Behavior)

By Laura Mauldin and Robyn Lewis Brown

Mauldin, Laura, and Tara Fannon. 2020. “They Told Me My Name: Developing a Deaf Identity." Symbolic Interaction. Online First.

McRuer, Robert. 2018. Crip Times: Disability, Globalization, and Resistance. New York, NY: NYU Press.

Meade, Michelle A., Elham Mahmoudi, and Shoou-Yih Lee. 2015. "The Intersection of Disability and Healthcare Disparities: A Conceptual Framework.” Disability and Rehabilitation 37(7):632-41.

Merikangas, Kathleen R., Minnie Ames, Lihong Cui, Paul E. Stang, T. Bedirhan Ustun, Michael Von Korff, and Ronald C. Kessler. 2007. "The Impact of Comorbidity of Mental and Physical Conditions on Role Disability in the US Adult Household Population." Archives of General Psychiatry 64(10): 1180-1188.Minich, Julie Avril. 2016. "Enabling Whom? Critical Disability Studies Now." Lateral: Journal of the Cultural Studies Association $5(1)$.

Mitchell, David T., and Sharon L. Snyder. 2015. The Biopolitics of Disability: Neoliberalism, Ablenationalism, and Peripheral Embodiment. Ann Arbor, MI: University of Michigan Press.

Moser, Ingunn. 2006. "Disability and the Promises of Technology: Technology, Subjectivity and Embodiment within an Order of the Normal." Information, Communication \& Society 9(3):373-95.

Naples, Nancy A., Laura Mauldin, and Heather Dillaway. 2019. "From the Guest Editors: Gender, Disability, and Intersectionality." Gender \& Society 33(1):5-18.

National Council on Disability (NCD). 2017. "Highlighting Disability / Poverty Connection." Washington DC: National Council on Disability. Retrieved July 15, 2020. (https://ncd.gov/newsroom/2017/disability-poverty-connection-2017-progress-reportrelease).

Okeke-Adeyanju, Naidi, Lorraine C. Taylor, Ashley B. Craig, Rachel E. Smith, Aqiyla Thomas, Alaina E. Boyle, and Melissa E. DeRosier. 2014. "Celebrating the Strengths of Black Youth: Increasing Self-Esteem and Implications for Prevention." The Journal of Primary Prevention 35(5):357-69.

Oliver, Michael. 1998. "Theories of Disability in Health Practice and Research." BMJ : British Medical Journal 317(7170):1446-49.

Oliver, Mike. 1992. "Changing the Social Relations of Research Production?” Disability, Handicap \& Society 7(2):101-14.

Parsons, Talcott. 1951. The Social System. Glencoe, IL: Free Press. 
Missing Pieces: Engaging Sociology of Disability in Medical Sociology (Forthcoming in Journal of Health and Social Behavior)

By Laura Mauldin and Robyn Lewis Brown

Peace, William J. 2012. “Comfort Care as Denial of Personhood.” Hastings Center Report 42(4):14-17.

Perry, Brea L., Kathi L. H. Harp, and Carrie B. Oser. 2013. "Racial and Gender Discrimination in the Stress Process: Implications for African American Women's Health and Wellbeing." Sociological Perspectives 56(1):25-48.

Phelan, Jo C., Bruce G. Link, Ana Diez-Roux, Ichiro Kawachi, and Bruce Levin. 2004. "“Fundamental Causes" of Social Inequalities in Mortality: A Test of the Theory." Journal of Health and Social Behavior 45(3):265-85.

Phelan, Jo C., Bruce G. Link, and John F. Dovidio. 2008. "Stigma and Prejudice: One Animal or Two?" Social Science \& Medicine 67(3): 358-367.

Roberts, Kim. 2020. “Austin Hospital Withheld Treatment from Disabled Man Who Contracted Coronavirus." The Texan, June 29. https://thetexan.news/austin-hospital-withheldtreatment-from-disabled-man-who-contracted-coronavirus/.

Romero, Mary. 2020. "Sociology Engaged in Social Justice.” American Sociological Review 85(1):1-30.

Rothman, Barbara Katz. 1993. The Tentative Pregnancy: How Amniocentesis Changes the Experience of Motherhood. New York, NY: W. W. Norton \& Company.

Saxton, Marsha. 2000. "Why Members of the Disability Community Oppose Prenatal Diagnosis and Selective Abortion." Pp. 147-64 in Prenatal Testing and Disability Rights, edited by E. Parens and A. Asch. Washington, D.C.: Georgetown University Press.

Scambler, Graham, and Sasha Scambler. 2010. "Introduction: The Sociology of Chronic and Disabling Conditions; Assaults on the Lifeworld." Pp. 1-7 in New Directions in the Sociology of Chronic and Disabling Conditions: Assaults on the Lifeworld, edited by G. Scambler and S. Scambler. New York, NY: Palgrave Macmillan.

Schalk, Sami. 2017. "Critical Disability Studies as Methodology." Lateral: Journal of the Cultural Studies Association 6(1).

Scotch, Richard. 2002. "Paradigms of American Social Research on Disability: What's New?" Disability Studies Quarterly 22(2).

Shakespeare, Tom. 2006. Disability Rights and Wrongs. New York, NY: Routledge.

Shakespeare, Tom. 2013. "The Social Model of Disability." Pp. 214-21 in The Disability Studies Reader, edited by L. J. Davis. New York, NY: Routledge.

Shapiro, Joseph P. 1994. No Pity: People with Disabilities Forging a New Civil Rights Movement. New York: Broadway Books. 
Missing Pieces: Engaging Sociology of Disability in Medical Sociology (Forthcoming in Journal of Health and Social Behavior)

By Laura Mauldin and Robyn Lewis Brown

Shandra, Carrie L., Dennis P. Hogan, and Susan E. Short. 2014. "Planning for Motherhood: Fertility Attitudes, Desires and Intentions Among Women with Disabilities." Perspectives on Sexual and Reproductive Health 46(4):203-10.

Shifrer, Dara. 2013. "Stigma of a Label: Educational Expectations for High School Students Labeled with Learning Disabilities." Journal of Health and Social Behavior 54(4):46280 .

Stapleton, David C., Bonnie L. O’Day, Gina A. Livermore, and Andrew J. Imparato. 2006. "Dismantling the Poverty Trap: Disability Policy for the Twenty-First Century." The Milbank Quarterly 84(4):701-32.

Steinmetz, Erika. 2006. “Americans With Disabilities: 2002.” Report Number P70-107. Washington, D.C.: U.S. Census Bureau.

Stoll, Laurie Cooper, and Justine Egner. 2021. "We Must Do Better: Ableism and Fatphobia in Sociology.” Sociology Compass 15:e12869.

Susman, Joan. 1994. "Disability, Stigma and Deviance.” Social Science \& Medicine 38(1):1522.

Taylor, Danielle M. 2018. “Americans with Disabilities: 2014.” Washington, DC: US Census Bureau. Retrieved July 11, 2020. (https://www.census.gov/library/publications/2018/demo/p70-152.html).

Thoits, Peggy A. 2010. "Stress and Health: Major Findings and Policy Implications." Journal of Health and Social Behavior 51(1): S41-S53. 2016. ““'I'm Not Mentally Ill”: Identity Deflection as a Form of Stigma Resistance." Journal of Health and Social Behavior 57(2):135-51.

Thomas, Carol. 2007. Sociologies of Disability and Illness: Contested Ideas in Disability Studies and Medical Sociology. New York, NY: Palgrave.

Umberson, Debra, Mieke Beth Thomeer, Corinne Reczek, and Rachel Donnelly. 2016. "Physical Illness in Gay, Lesbian, and Heterosexual Marriages: Gendered Dyadic Experiences." Journal of Health and Social Behavior 57(4):517-31.

Vastag, Brian, and Beth Mazur. 2020. "Perspective: Researchers Warn Covid-19 Could Cause Debilitating Long-Term Illness in Some Patients." Washington Post, May 30. https://www.washingtonpost.com/health/could-covid-19-cause-long-term-chronicfatigue-and-illness-in-some-patients/2020/05/29/bcd5edb2-a02c-11ea-b5c9570a91917d8d_story.html 
Missing Pieces: Engaging Sociology of Disability in Medical Sociology (Forthcoming in Journal of Health and Social Behavior)

By Laura Mauldin and Robyn Lewis Brown

Vincent, Grayson K., and Victoria A. Velkoff. 2010. The Next Four Decades: The Older Population in the United States : 2010 to 2050. Washington DC: U.S. Department of Commerce, Economics and Statistics Administration, and U.S. Census Bureau.

Winance, Myriam. 2016. "Trying Out the Wheelchair: The Mutual Shaping of People and Devices through Adjustment." Science, Technology, \& Human Values 31(1):52-72.

Wolbring, Gregor. 2008. “The Politics of Ableism.” Development 51(2):252-58.

Wong, Alice. 2020. “\#Coronavirus and the disability community.” Wakelet. Retrieved April 30, 2021. https://wakelet.com/wake/1633ef52-2ade-43a9-b118-50d19f821cb7

Zola, Irving Kenneth 1972. "Medicine as an Institution of Social Control." The Sociological Review 20(4):487-504.

Zola, Irving Kenneth. 1982. Missing Pieces: A Chronicle of Living with a Disability. Philadelphia, PA: Temple University Press.

Zola, Irving Kenneth. 1991. "Bringing Our Bodies and Ourselves Back In: Reflections on a Past, Present, and Future "Medical Sociology."” Journal of Health and Social Behavior 32(1):1-16. 